\title{
Chronic pain, pain severity and analgesia use in Australian women of reproductive age
}

\author{
April M. Miller ${ }^{\mathrm{a}}$, Kristy Sanderson ${ }^{\mathrm{a}, \mathrm{b}}$, Raimondo B. Bruno ${ }^{\mathrm{c}}$, Monique Breslin ${ }^{\mathrm{a}}$, \\ Amanda L. Neil ${ }^{\text {,** }}$ \\ a Menzies Institute for Medical Research, University of Tasmania, Hobart, Australia \\ ${ }^{\mathrm{b}}$ School of Health Sciences, University of East Anglia, Norwich, UK \\ ' School of Medicine, University of Tasmania, Hobart, Australia
}

\section{A R T I C L E I N F O}

\section{Article history:}

Received 14 January 2018

Received in revised form 29 May 2018

Accepted 24 June 2018

Available online $\mathrm{xxx}$

\section{Keywords:}

Reproductive age

Pregnant

Chronic pain

Pain severity

Opioid Analgesia

\begin{abstract}
A B S T R A C T
Background: The increasing prevalence and adverse outcomes associated with opioid analgesia use in women of reproductive age have become a significant public health issue internationally, with use during pregnancy potentially affecting maternal and infant health outcomes.

Objective: This study aims to provide national estimates of chronic pain, pain severity and analgesia use in Australian women of reproductive age by pregnancy status.

Method: Data were obtained from the Australian Bureau of Statistics 2011-12 National Health Survey $(n=20,426)$. Weighting was applied to sample data to obtain population estimates. For this study data were analysed for pregnant $(n=166, N=192,617)$ and non-pregnant women $(n=4710, N=5,256,154)$ of reproductive age (15-49 years).

Results: Chronic or reoccurring pain was reported in $5.1 \%$ of pregnant women and $9.7 \%$ of non-pregnant women, and $0.7 \%$ and $2.6 \%$ of pregnant and non-pregnant women reported recent opioid analgesia use respectively. Moderate-to-very severe pain was more common in pregnant than non-pregnant women taking opioid analgesics, and no pain and very mild-to-mild pain in non-pregnant women.

Conclusion: Approximately 1 in 20 pregnant Australian women have chronic or reoccurring pain. Opioid analgesia was used by around $1 \%$ of Australian pregnant women during a two-week period, with use associated with moderate-to-very severe pain. Given that the safety of many analgesic medications in pregnancy remains unknown, pregnant women and health professionals require accurate, up-to-date information on the risks and benefits of analgesic use during pregnancy. Further evidence on the decision-making processes of pregnant women with pain should assist health professionals maximise outcomes for mothers and infants.
\end{abstract}

(C) 2018 Published by Elsevier Ltd on behalf of Australian College of Midwives.

\section{Statement of significance}

\section{Problem or issue}

There have been significant increases in the use of opioid analgesia internationally, including in women of reproductive age. The prevalence of pain and opioid analgesia use in Australian pregnant women remains unknown.

\footnotetext{
* Corresponding author at: Menzies Institute for Medical Research, University of Tasmania, Private Bag 23, Hobart, Tasmania, 7001, Australia.

E-mail address: Amanda.Neil@utas.edu.au (A.L. Neil).
}

\section{What is already known}

Chronic pain in women of reproductive age is not uncommon and is often associated with the use of analgesic medications, including opioid analgesia. In the US and Canada, the increasing use of opioid analgesic medications in pregnant and reproductive aged women has become a major public health issue, leading to significant impacts upon maternal and infant health outcomes.

\section{What this paper adds}

We establish that in Australia, 1 in 20 pregnant women have experienced chronic or reoccurring pain over the most recent six-month period. Further, around $1 \%$ of pregnant women reported recent use of opioid analgesic medications 
and this use was associated with moderate-to-very severe pain.

\section{Introduction}

Sex differences in both pain frequency and intensity have been well described in the international literature. Women are disproportionately or even solely affected by many conditions which cause or contribute to chronic pain. ${ }^{1}$ Many of these conditions are more likely to occur during the reproductive years than at any other time of life. ${ }^{1}$ Thus, while it is well known that the prevalence of chronic pain increases with older age, chronic pain in women of reproductive age is not uncommon. ${ }^{2,3}$

During pregnancy pain may occur as a result of an existing health condition, due to an underlying medical illness, or as a consequence of physiological changes associated with pregnancy. ${ }^{4-8}$ In some cases women may have chronic pain of multiple aetiologies, including pre-pregnancy pain conditions, which have become exacerbated by the developing pregnancy. ${ }^{9,10}$

Though not exhaustive, examples of health conditions and illnesses which may cause chronic or reoccurring pain in women during the reproductive years include: systemic lupus erythematosus, rheumatoid arthritis, ${ }^{11}$ the Ehlers-Danlos syndromes, ${ }^{12}$ temporomandibular disorder, ${ }^{13}$ reoccurring migraine, ${ }^{14}$ chronic back pain, ${ }^{15,16}$ fibromyalgia, ${ }^{17,18}$ Crohn's disease, ulcerative colitis, ${ }^{19}$ endometriosis and other causes of chronic pelvic pain, both gynaecologic and non-gynaecologic. ${ }^{20,21}$ For the majority of these conditions prevalence rates specific to pregnant women are not known.

Pregnancy related pain and discomfort are common and may include conditions such as lower back pain and pelvic joint pain. ${ }^{22,23}$ Pregnancy can be an especially difficult period for women with severe pain. ${ }^{24}$ In a sample of South Australian women interviewed retrospectively, $61 \%$ of women described the lower back pain they experienced in pregnancy as moderately severe, with a further $9 \%$ reporting their pain as so severe it was completely debilitating. ${ }^{24}$ Women with pregnancy-related symphysis pubis dysfunction also often report experiencing extreme, ongoing pain, which can have a substantial impact upon quality of life. ${ }^{25}$

Many women with painful health conditions may have an ongoing requirement for analgesic medications, including during pregnancy. ${ }^{5,26}$ However, the safety of many analgesic medications during pregnancy has not been definitively established. ${ }^{4,8}$

The use of opioid analgesic medications for chronic pain management in the general population has been the source of much research. Their use remains an issue of debate due primarily to concerns pertaining to safety and the effectiveness of treatment, particularly in populations at high risk of adverse events. ${ }^{27}$ One concern is the increasing use of opioid analgesic medications among women of childbearing age. This phenomenon has been documented in both the United States ${ }^{28,29}$ and Canada, ${ }^{30}$ where prescription opioid use and abuse has been described as being at epidemic proportions. A recent study by Patrick et al. highlighted that almost one third of pregnant women had filled a prescription for at least one opioid analgesic medication during pregnancy, contributing to neonatal complications including low birth weight and neonatal abstinence syndrome (NAS). ${ }^{29}$ Other reports of the prevalence of opioid use during pregnancy range from $6 \%$ in Norway $^{31}$ to an estimated $41 \%$ in some areas of the United States. ${ }^{32}$

The outcomes of foetal exposure to maternal medication use are dependent upon the stage of embryonic or foetal development, in addition to maternal and placental clearance of the medication. ${ }^{33,34}$ The early stages of the first trimester of pregnancy are a critical period of embryogenesis. ${ }^{4}$ Many teratogenic effects which are associated with medication exposures occur during this period, potentially before many women realise they are pregnant. ${ }^{4}$ Though opioid medications were thought to have no association with an increased risk of congenital malformations, more recent observational studies have found associations between opioid analgesia use during pregnancy and several birth defects, including multiple congenital heart defects, neural tube defects and abdominal wall defects such as gastroschisis. ${ }^{5-8,35}$

This study aims to provide the first nationally representative data on the prevalence of chronic pain, pain severity and analgesia use in Australian women of reproductive age by pregnancy status.

\section{Methods}

Data were obtained from the 2011-12 Australian National Health Survey (NHS) in which data were collected using a stratified multistage area sample $(n=20,426)$ across Australia. ${ }^{36}$ Interviews were conducted face-to-face in the participants' homes between March 2011 and March 2012. ${ }^{37}$ Sample results were weighted to infer an Australian population estimate at the time of the survey $(\mathrm{N}=22,105,281)$. For this study, data were analysed for the weighted population of pregnant $(\mathrm{N}=192,617)$ and non-pregnant women $(N=5,256,154)$ in Australia aged $15-49$ years. Data items analysed comprised chronic or recurring pain in the previous six months, bodily pain (severity), opioid analgesia and non-opioid analgesia use.

Pregnancy status was self-reported. Females aged 10 years and over were asked if any of the following applied: have never menstruated, currently pregnant, currently breast feeding, currently experiencing menopause or post menopause. ${ }^{38}$ Women who did not meet any of these specific life stages were coded as 'none apply'. ${ }^{38}$ Information on pregnancy trimester or gestation was not reported.

Pain severity was assessed by self-report over a duration of four weeks prior to the survey and classified into four groups for the purposes of this study; no pain, very mild to mild pain, moderate to very severe pain and not applicable or unknown.

Participants of the Australian NHS were asked for the name of all medications they had taken in the last two weeks. It was requested that participants provide the packages of all recently taken medications to the interviewer to verify medication name. Medications within the NHS were classified using the World Health Organisation's (WHO) Anatomical Therapeutic Chemical (ATC) system. The ATC classification system categorises drugs into different groups by either the organ or system on which they act, as well as their associated pharmacologic and therapeutic properties. ${ }^{39}$ Opioid analgesia use included the use of any type of opioid analgesia over the previous two-week period. Non-opioid analgesia use included the use of any type of pharmaceutical non-opioid analgesic medications and anti-migraine medications over the previous two-week period. The survey did not distinguish between medications that were prescribed or purchased 'over the counter'.

Data specific to chronic pain was provided directly from the Australian Bureau of Statistics (ABS) by special request, as this data was not released as part of the NHS Confidentialised Unit Record File (CURF). All other data were extracted from the 2011-2012 Australian NHS CURF and ABS Tablebuilder tool.

Cross-tabulations were performed to establish the prevalence of bodily pain, as well as the prevalence of opioid and other analgesia use among women of reproductive age in the NHS sample. STATA v12 was used for analysis. ABS established weighting was applied to calculate a population estimate and associated confidence interval for the identified pain and medication use prevalence rates. The Jackknife delete- 1 weighting method is recommended by the ABS for use with these and 
similar survey data to account for the survey design used and reduce potential bias. ${ }^{40}$ All analysis requiring data specific to chronic pain were performed by the ABS for the purposes of this study. Differences between pregnant and non-pregnant groups of women were tested for significance. A p-value of $\leq 0.05$ was regarded as statistically significant.

\subsection{Ethics}

All interview components of the NHS were conducted by the Australian Bureau of Statistics staff under the Census and Statistics Act 1905. These data are made available by the ABS in a CURF. Each CURF contains detailed participant data collected by the ABS during the Census and other surveys. This data is then made available at the discretion of the ABS. Analysis of the CURF data were undertaken by authors who are registered users of the NHS CURF. As access to chronic pain data was restricted and not available as part of the CURF, all analyses of chronic pain data presented were conducted by the ABS for this study.

\section{Results}

\subsection{Demographics of pregnant and non-pregnant women}

Population estimates of demographic information for Australian women are included in Table 1. Of women aged 15-49 years, the mean age of pregnant women was 30 years and that of nonpregnant women 32 years. History of comorbidity was similar across both groups, with a few exceptions. Asthma, cardiovascular issues, arthritis, mental health and 'other' health issues were reported by greater percentages of women who were not pregnant at the time of the survey. Most women from both groups had never smoked (58.2\% for pregnant women and $60.2 \%$ for non-pregnant women).

\subsection{Prevalence of pain in women of reproductive age}

The percentage of non-pregnant Australian women aged 15-49 years with chronic or reoccurring pain (for at least a six-month period) was estimated at $9.7 \%$, compared to $5.0 \%$ of women who were identified as pregnant at the time of the survey.

Very mild to mild pain was the most common severity of bodily pain reported in pregnant $(52.4 \%)$ and non-pregnant women (40.1\%), which was found to be a statistically significant difference $(p=0.023)$ (Fig. 1). Moderate to very severe pain was experienced by $17.6 \%$ of pregnant women and $22.1 \%$ of non-pregnant women $(p=0.296)$. The percentage of pregnant and non-pregnant women experiencing no pain during the four weeks prior to the interview were similar $(29.6 \%$ and $29.7 \%$ respectively; $\mathrm{p}=0.990)$.

\subsection{Use of opioid and non-opioid analgesia in women of reproductive age with pain}

Population estimates indicate that 1383 (0.7\%) of pregnant women and 138,962 (2.6\%) of non-pregnant women aged 15-49 years had taken opioid analgesia within the two weeks prior to the

Table 1

Weighted population estimates of demographic characteristics.

\begin{tabular}{|c|c|c|c|c|}
\hline \multicolumn{5}{|l|}{ Females aged $15-49$ years } \\
\hline \multirow[b]{2}{*}{ Age (years) } & \multicolumn{2}{|c|}{ Pregnant women $(n=166, N=192,617)$} & \multicolumn{2}{|c|}{ Non-pregnant women $(\mathrm{n}=4710, \mathrm{~N}=5,256,154)$} \\
\hline & 30.3 & $(29.3-31.3)$ & 32.3 & $(32.2-32.3)$ \\
\hline $15-19$ & 2.3 & $(1.6-6.2)$ & 14.2 & $(13.0-15.3)$ \\
\hline $20-24$ & 13.9 & $(5.8-22.1)$ & 13.5 & $(12.3-14.6)$ \\
\hline $25-29$ & 30.9 & $(21.5-40.3)$ & 14.5 & $(14.1-14.9)$ \\
\hline $30-34$ & 32.3 & $(23.4-41.2)$ & 13.6 & $(13.3-13.9)$ \\
\hline $35-39$ & 16.1 & $(9.7-22.6)$ & 14.4 & $(14.1-14.6)$ \\
\hline $40-44$ & 3.5 & $(0.2-6.8)$ & 15.1 & $(15.0-15.2)$ \\
\hline $45-49$ & 0.9 & $(0.0-2.8)$ & 14.8 & $(14.6-14.9)$ \\
\hline \multicolumn{5}{|l|}{ Marital Status } \\
\hline Never married & 25.9 & $(16.6-35.1)$ & 49.0 & $(47.5-50.5)$ \\
\hline Widowed & 0.0 & - & 0.3 & $(0.2-0.5)$ \\
\hline Divorced & 2.9 & $(0.0-5.8)$ & 4.9 & $(4.2-5.7)$ \\
\hline Separated & 0.7 & $(0.0-2.0)$ & 3.2 & $(2.6-3.8)$ \\
\hline Married & 71.5 & $(60.5-80.6)$ & 42.5 & $(40.9-44.2)$ \\
\hline \multicolumn{5}{|l|}{ History of comorbidity } \\
\hline Asthma & 16.7 & $(10.5-22.9)$ & 23.1 & $(21.4-24.8)$ \\
\hline Cancer & 5.8 & $(1.0-10.6)$ & 5.2 & $(4.5-5.9)$ \\
\hline Cardiovascular & 16.1 & $(9.2-22.9)$ & 23.9 & $(22.2-25.7)$ \\
\hline Arthritis & 2.2 & $(0.0-6.1)$ & 6.3 & $(5.6-7.0)$ \\
\hline Osteoporosis & 1.1 & $(0.0-3.1)$ & 0.8 & $(0.5-1.1)$ \\
\hline Diabetes & 10.3 & $(2.9-17.8)$ & 7.3 & $(6.4-8.2)$ \\
\hline Kidney disease & 1.0 & $(0.0-2.6)$ & 1.4 & $(1.0-1.8)$ \\
\hline Sight/hearing & 55.5 & $(46.0-65.1)$ & 53.0 & $(51.2-54.9)$ \\
\hline Mental wellbeing & 7.3 & $(2.4-12.1)$ & 17.4 & $(16.0-18.9)$ \\
\hline Other conditions ${ }^{\mathrm{a}}$ & 43.3 & $(34.0-52.5)$ & 58.7 & $(56.7-60.7)$ \\
\hline No conditions & 14.6 & $(7.4-21.7)$ & 14.0 & $(12.5-15.4)$ \\
\hline \multicolumn{5}{|l|}{ Smoker } \\
\hline Current daily smoker & 9.3 & $(2.4-16.2)$ & 15.9 & $(14.7-17.1)$ \\
\hline Past daily smoker, still smoking & 0.0 & - & 1.4 & $(0.8-2.0)$ \\
\hline Past daily smoker, ex-smoker & 28.9 & $(21.2-36.5)$ & 18.5 & $(17.1-20.0)$ \\
\hline Never smoked daily & 3.6 & $(0.7-6.5)$ & 4.0 & $(3.4-4.6)$ \\
\hline Never smoked & 58.2 & $(48.4-68.1)$ & 60.2 & $(58.5-61.8)$ \\
\hline
\end{tabular}

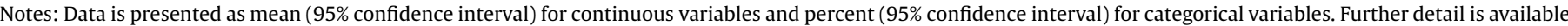
at Australian Bureau of Statistics ${ }^{54}$.

a Other conditions' consisted of over 20 other long-term health conditions including; sinusitis, food allergy, drug allergy, anaemia, epilepsy, migraine and psoriasis. 


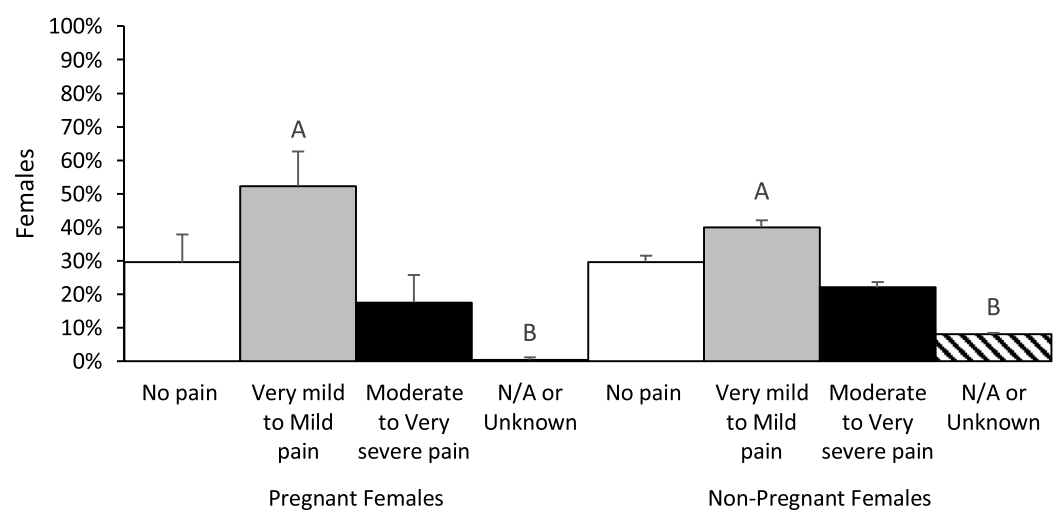

15 - 49 years

Fig. 1. Pain severity during previous four weeks by pregnancy status in women aged 15-49 years.

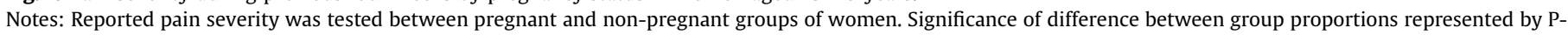
values; $\mathrm{A}<0.05 ; \mathrm{B}<0.001$. Error bars represent $95 \%$ confidence intervals for estimates.

survey. In pregnant women who had chronic pain, $13.7 \%$ had used analgesia (opioid and non-opioid), compared with $27.3 \%$ of nonpregnant women of reproductive age with chronic pain. One hundred percent of women reporting the use of opioid analgesia during pregnancy had pain which was described as moderate to very severe (Fig. 2a). In non-pregnant women, most women who took opioids reported moderate to very severe pain (66.0\%), followed by very mild to mild pain (25.5\%) and then no pain $(6.1 \%)$. The pain status of a small proportion of non-pregnant women using opioid medications was not known.
Pregnant women were significantly more likely to report moderate to very severe pain when taking opioid analgesia than non-pregnant women of reproductive age ( $p<0.001$ ), whilst nonpregnant women were significantly more likely to report no pain $(p=0.005)$ or very mild to mild pain $(p<0.001)$ (Fig. $2 a)$. Of all pregnant women with moderate to very severe pain $4.1 \%$ took opioid analgesia; and of non-pregnant women with moderate to very severe pain $7.9 \%$ took opioid analgesia.

Estimates of non-opioid analgesia use indicate that 10,024 (5.2\%) pregnant women and 547,731 (10.4\%) non-pregnant women

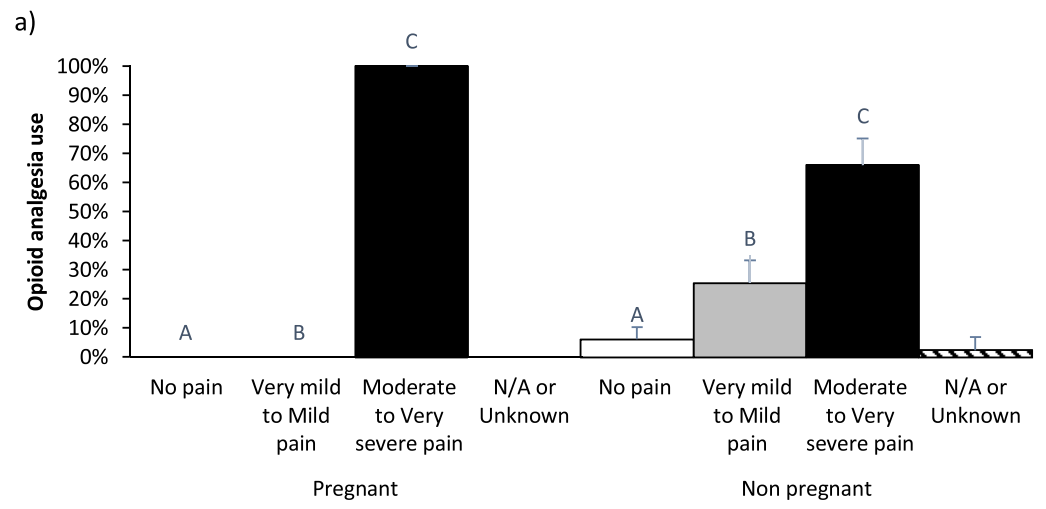

b)

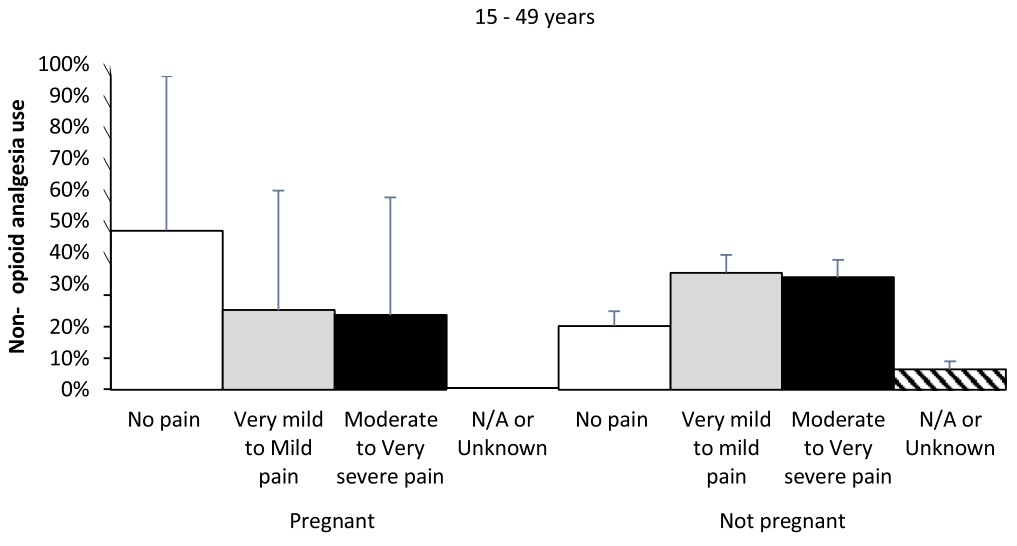

15 - 49 years

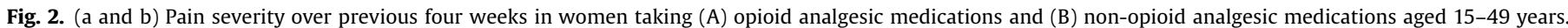

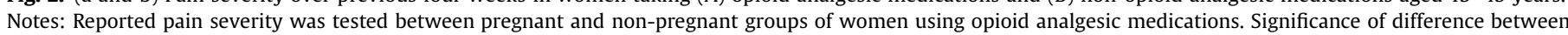
proportions represented by P-values; $\mathrm{A}<0.05$; $\mathrm{B}<0.001$; $\mathrm{C}<0.001$. Error bars represent $95 \%$ confidence intervals for estimates. 
had recently taken non-opioid analgesia. Pregnant women both with and without pain used non-opioid analgesia during the two weeks prior to the interview, with the majority (50.8\%) reporting no pain over the previous four weeks (Fig. 2b). As seen in this figure, confidence intervals for pregnancy and non-opioid analgesia use were wide.

One quarter (25.8\%) of pregnant women using non-opioid analgesia experienced very mild to mild pain and $23.8 \%$ reported moderate to very severe pain. One in five $(20.3 \%)$ non-pregnant women reported using non-opioid analgesia in the previous two weeks when they had no pain. This proportion increased to $37.6 \%$ for non-pregnant women with very mild to mild pain and $35.9 \%$ for moderate to very severe pain. The pain status of a small proportion of women aged 15 to 49 years taking non-opioid analgesia was not known. There were no significant differences in pain severity between pregnant and non-pregnant women taking non-opioid analgesia in this study.

\section{Discussion}

Internationally, the prevalence of chronic pain in pregnant women has not been widely reported, although it is an issue gaining more recognition in the literature. ${ }^{4,5,41}$ Based on the Australian NHS we estimate that twice as many non-pregnant women of reproductive age suffer from chronic or reoccurring pain than women who are pregnant, at $10 \%$ and $5 \%$ respectively. For non-pregnant women this is at the lower end of previous Australian estimates which ranged between $10-17 \%$ across this age-group. ${ }^{2}$ Some of the difference between groups seen in the current study may be explained by higher reported prevalence of specific chronic conditions in non-pregnant women, such as arthritis.

An estimated $17 \%$ of pregnant women and $22 \%$ of nonpregnant women experienced moderate to very severe pain in the most recent four weeks. There were no pregnant women who reported experiencing very severe pain. It is possible that any pregnant woman experiencing such a severe degree of pain would be hospitalised for further investigation and as a result, would not have participated in the survey. Absence of pregnant women with very severe pain in these results may also indicate that women with pain of such severity may not consider pregnancy due to the increased physical burden they may face, including their perceived ability to care for the infant. Indeed, the adverse effects of severe pain on the quality of life of sufferers are well acknowledged. ${ }^{42,43}$ Yet, results of the few studies exploring attitudes towards pregnancy in women living with chronic, painful conditions have found that many women do not necessarily see their condition as an absolute deterrent to pregnancy. ${ }^{44,45} \mathrm{~A}$ further consideration is that perception of pain severity may differ between pregnant and non-pregnant women. This issue has not been well researched. It is possible that each of these factors (and potentially many others) play a role in the differences observed in this study.

Given constraints on the release of chronic pain data by the ABS we were unable to determine the exact proportion of pregnant women with chronic pain who were taking opioid analgesia. However, we did ascertain that almost $14 \%$ of pregnant women and almost double, $27 \%$ of non-pregnant women who experienced chronic pain had taken some form of analgesic medication (opioid and/or non-opioid) within the most recent two-week period. In other Australian research reporting prevalence of analgesia use in pregnancy, a 2002-05 Western Australian study revealed that 8.3\% of prescriptions dispensed during pregnancy were for analgesic medications. ${ }^{46}$ However, as the data related to prescriptions rather than the population who were pregnant, it is not possible to directly compare these findings with the current study.
As moderate to severe pain is the established clinical indication for the prescribing of opioid analgesic medications, it was a reassuring finding that women who reported moderate to very severe levels of pain were found to have the highest prevalence of opioid analgesia use. When looking at all pregnant women who reported pain over the previous four weeks, only four percent of those who had moderate to very severe pain reported the use of opioid analgesic medications. In the sample, these women were all taking codeine combination medications. Codeine is available alone, or in combination with paracetamol or ibuprofen in Australia. At the time the data was collected for this study, many lower dose codeine-combination formulations (i.e. $\leq 15 \mathrm{mg}$ codeine per tablet) were still available without a prescription. However, from February 2018, all codeine medications must be prescribed by a doctor. Risk of infant withdrawal with low dose codeine medications is still possible with prolonged use in late pregnancy. $^{47}$

In non-pregnant women, a quarter of all those with very mild to mild levels of pain, and $10 \%$ of those who reported no pain at all over the previous four weeks reported recently taking opioid analgesic medication. These medications included: codeine, tramadol, oxycodone, buprenorphine and morphine. Interestingly, the survey did not capture any women of reproductive age who reported their opioid medication use was for opioid maintenance therapy to treat substance dependence. As a result, the reasons for use in women with no or very mild to mild pain is unclear. However, recall bias and reporting bias may be attributing factors.

Non-opioid analgesics are some of the most commonly used medications during the pregnancy period. ${ }^{48}$ Previous Australian estimates have reported that over half of pregnant women had taken non-opioid analgesia during at least one trimester of pregnancy. ${ }^{49}$ The current study reported a lower overall estimate at $5 \%$ of pregnant women, which may be reflective of both the duration of reported medication use as well as recall bias.

Examination of pain status alongside non-opioid analgesia use in the current study provided some divergent results. For instance, less than a quarter of pregnant women with moderate to very severe pain reported the use of any non-opioid analgesia whereas, over half of pregnant women who stated they had taken non-opioid analgesia over the last two weeks reported no pain. It could be argued that medications such as paracetamol may have been utilised for their antipyretic properties. However, it is unlikely that use in this manner accounts for all women who reported using non-opioid analgesia whilst pregnant. These results may suggest that women consider non-opioid medications as 'safe' overall during pregnancy. This is not always the case. Non-steroidal anti-inflammatory drugs have recently been identified as a causal factor in increased risk of miscarriage, even if only taken around the time of conception. ${ }^{50}$ Paracetamol has also caused concern, with associations made between use in pregnancy and subsequent development of asthma ${ }^{51}$ and behavioural problems ${ }^{52}$ in childhood.

The strengths of this study include the use of data collected in a robust and rigorous manner by trained staff of the Australian Bureau of Statistics as part of the 2011-12 Australian National Health Survey. The NHS as part of the Australian Health Survey is the largest, most extensive health survey ever conducted in Australia, with a response rate of over $80 \%$. It is the most recent NHS for which pregnancy status was assessed, as this detail was not included in the 2014-15 version of the survey.

Regarding study limitations, the Australian NHS survey relies mainly upon self-reported data. While this may be less of an issue for variables such as chronic pain or pain severity, where selfreport is considered the gold standard, it could be argued that self-report of medication use may not be as robust a measure as methods such as medical record audit or utilising linked 
prescription data. ${ }^{53}$ This may be an issue in pregnancy, when women may not disclose or may underreport the use of substances (both legal and illegal). However, the fact that participants were asked to provide the interviewer with the medications they had taken over the previous two weeks lends strength to the study, improving the quality of the data collected over self-reported medication use alone. Irrespective, as medication data were recorded by ATC classification alone, it was not possible to distinguish between analgesic medications available over the counter or those which are only available by prescription. This study also only captured the use of analgesic medications over a two-week period out of an entire pregnancy, usually around 40 weeks duration. Therefore, our results will likely underestimate the true proportion of Australian women of childbearing age who take opioid or non-opioid analgesia during their pregnancy.

It is also possible that women who participated in the survey may have been pregnant but unaware at the time of the survey or be unwilling to disclose their pregnancy to the interviewer when asked. It is also important to acknowledge that prevalence of chronic pain increases with age whilst fecundity decreases. Thus, the prevalence of chronic pain in this study is likely to be inherently higher in the non-pregnant group as the group of pregnant women had proportionally fewer participants aged 40 to 49 years. The option of adjusting for age in the comparison, was not possible due to the constraints on statistical analysis of the data, including pre-analysis of the chronic pain data for us by the ABS. Large relative standard errors for some chronic pain data were due to the small number of participants and likewise large confidence intervals in data for pregnant women, suggesting that some weighted estimates should be used with caution. Some confidence intervals have been truncated in Table 1 and Fig. 2 where illogical results were obtained (i.e. greater than $100 \%$ or less than $0 \%$ ). This circumstance arose as part of the weighting process due to the small sample size of the pregnant group. We were not able to distinguish whether the reported severity of bodily pain improved or changed because of recent analgesia use. Nor were we able to establish whether the pain which was reported preceded pregnancy or vice versa.

The results of this study also raise questions about decision making in relation to pain treatment in pregnant women. Does perceived pain need to be more severe for pregnant women to consider taking strong analgesic medications during pregnancy? Are pregnant women more likely to remain untreated, even for pain which is moderate to very severe? If so, do we need to increase access to information and education on safety of pain relief during pregnancy?

\section{Conclusion}

Approximately 1 in 20 women have chronic pain during pregnancy in Australia. Opioid analgesia use was reported by around $1 \%$ of pregnant Australian women and non-opioid analgesia by $5 \%$ over a two-week duration. Use of opioids in Australian pregnant women is associated with moderate to very severe pain, whilst use of non-opioid analgesia is not always used in association with pain. However, the true number of women of reproductive age who are taking opioid analgesia may be much higher than the results of this study suggest. Irrespective of prevalence, all women taking medication during pregnancy require, at the very minimum, accurate, up-to-date information on the risks and benefits of their specific medication. In turn, health professionals need further evidence on pain and the use of opioid analgesia during pregnancy and more information on the decision-making processes of pregnant women experiencing pain to assist them with the care of their patients.

\section{Conflicts of interest}

Ms Miller, Professor Sanderson and Dr Breslin have no conflicts of interest to declare. Dr Neil would like to acknowledge that she lives with a chronic pain condition. Associate Professor Bruno has been an investigator on untied investigator driven educational grants from Reckitt Benckiser and has received an untied educational grant from Mundipharma for post-marketing surveillance studies of Reformulated OxyContin ${ }^{\mathbb{R}}$. These untied grants are all unrelated to the current study which has been submitted for consideration to your journal.

\section{Acknowledgements}

The authors wish to acknowledge the comments and feedback provided by Professor Peter Dargaville during preparation of the manuscript and the grant received by the Local Government Association of Tasmania which was used to fund the statistical analysis of chronic pain related data by the Australian Bureau of Statistics. AM's work was supported by an Australian Postgraduate Award Scholarship and a Staples Australia Konica Minolta Elite Research Scholarship. AN's work was supported by a Select Foundation Research Fellowship.

\section{References}

1. Meisler J.G.. Chronic pain conditions in women. J Womens Health 1999;8 (3):313-20.

2. Blyth FM, March LM, Brnabic AJ, Jorm LR, Williamson M, Cousins MJ. Chronic pain in Australia: a prevalence study. PAIN ${ }^{\mathbb{B}}$ 2001;89(2-3):127-34.

3. Australian Bureau of Statistics. Characteristics of Bodily Pain in Australia. 2012 http://www.abs.gov.au/ausstats/abs@.nsf/Lookup/4841.0Chapter12011. [Accessed 24 April 2015].

4. Coluzzi F, Valensise H, Sacco M, Allegri M. Chronic pain management in pregnancy and lactation. Minerva Anestesiol 2014;80(2):211-24.

5. Pritham UA, McKay L. Safe management of chronic pain in pregnancy in an era of opioid misuse and abuse. J Obstet Gynecol Neonatal Nurs 2014;43(5):554-67.

6. Brennan MC, Rayburn WF. Counseling about risks of congenital anomalies from prescription opioids. Birth Defects Res A Clin Mol Teratol 2012:94(8):620-5.

7. Kellogg A, Rose CH, Harms RH, Watson WJ. Current trends in narcotic use in pregnancy and neonatal outcomes. Am J Obstet Gynecol 2011;204(3) 259.e1-4.

8. Broussard CS, Rasmussen SA, Reefhuis J, et al. Maternal treatment with opioid analgesics and risk for birth defects. Am J Obstet Gynecol 2011;204(4) 314.e1-. e11.

9. Sharpe C, Kuschel C. Outcomes of infants born to mothers receiving methadone for pain management in pregnancy. Arch Dis Child Fetal Neonatal Ed 2004;89(1):F33-6.

10. Wunsch MJ, Stanard V, Schnoll SH. Treatment of pain in pregnancy. Clin J Pain 2003:19(3):148-55.

11. van Vollenhoven RF. Sex differences in rheumatoid arthritis: more than meets the eye. BMC Med 2009;7(1):12.

12. Castori M, Dordoni C, Valiante M, et al. Nosology and inheritance pattern(s) of joint hypermobility syndrome and Ehlers-Danlos syndrome, hypermobility type: a study of intrafamilial and interfamilial variability in 23 Italian pedigrees. Am J Med Genet A 2014;164(12):3010-20.

13. LeResche L. Epidemiology of temporomandibular disorders: implications for the investigation of etiologic factors. Crit Rev Oral Biol Med 1997:8(3):291-305.

14. Frederick IO, Qiu C-f, Enquobahrie DA, et al. Lifetime Prevalence and Correlates of Migraine among Women in a Pacific Northwest Pregnancy Cohort Study. Headache 2014;54(4):675-85.

15. Sabino J, Grauer JN. Pregnancy and low back pain. Curr Rev Musculoskelet Med 2008;1(2):137-41.

16. Mogren IM, Pohjanen AI. Low back pain and pelvic pain during pregnancy: prevalence and risk factors. Spine (Phila Pa 1976) 2005;30(8):983-91.

17. Weir PT, Harlan GA, Nkoy FL, et al. The incidence of fibromyalgia and its associated comorbidities: a population-based retrospective cohort study based on International Classification of Diseases, 9th Revision codes. J Clin Rheumatol 2006;12(3):124-8.

18. Wolfe F, Ross K, Anderson J, Russell IJ, Hebert L. The prevalence and characteristics of fibromyalgia in the general population. Arthritis Rheum 1995;38(1):19-28.

19. Beaulieu DB, Kane S. Inflammatory bowel disease in pregnancy. World J Gastroenterol 2011;17(22):2696-701.

20. Eskenazi B, Warner ML. Epidemiology of endometriosis. Obstet Gynecol Clin North Am 1997;24(2):235-58.

21. Ayorinde AA, Bhattacharya S, Druce KL, Jones GT, Macfarlane GJ. Chronic pelvic pain in women of reproductive and post-reproductive age: a population-based study. Eur J Pain 2017;21(3):445-55. 
22. Albert H, Godskesen M, Westergaard J. Prognosis in four syndromes of pregnancy-related pelvic pain. Acta Obstet Gynecol Scand 2001;80(6):505-10.

23. Gutke A, Östgaard HC, Öberg B. Predicting persistent pregnancy-related low back pain. Spine (Phila Pa 1976) 2008;33(12):E386-93.

24. Stapleton DB, MacLennan AH, Kristiansson P. The prevalence of recalled low back pain during and after pregnancy: a South Australian population survey. Aust N Z J Obstet Gynaecol 2002;42(5):482-5.

25. Jain S, Eedarapalli P, Jamjute P, Sawdy R. Symphysis pubis dysfunction: a practical approach to management. Obstet Gynaecol 2006;8(3):153-8.

26. Mogil JS. Pain genetics: past, present and future. Trends Genet 2012;28(6):25866.

27. Freynhagen R, Geisslinger G, Schug SA. Opioids for chronic non-cancer pain BMJ 2013;346:f2937.

28. Tolia VN, Patrick SW, Bennett MM, et al. Increasing incidence of the neonatal abstinence syndrome in U.S. neonatal ICUs. New Engl J Med 2015;372 (22):2118-26.

29. Patrick SW, Dudley J, Martin PR, et al. Prescription opioid epidemic and infant outcomes. Pediatrics 2015;135(5):842-50.

30. Turner SD, Gomes T, Camacho X, et al. Neonatal opioid withdrawal and antenatal opioid prescribing. CMAJ Open 2015;3(1):E55-61.

31. Engeland A, Bramness JG, Daltveit AK, Rønning M, Skurtveit S, Furu K Prescription drug use among fathers and mothers before and during pregnancy: a population-based cohort study of 106000 pregnancies in Norway 2004-2006. Br J Clin Pharmacol 2008;65(5):653-60.

32. Bateman BT, Hernandez-Diaz S, Rathmell JP, et al. Patterns of opioid utilization in pregnancy in a large cohort of commercial insurance beneficiaries in the United States. Anesthesiology 2014;120(5):1216-24.

33. Buhimschi CS, Weiner CP. Medications in pregnancy and lactation: part 1. Teratology. Obstet Gynecol 2009;113(1):166-88.

34. Rayburn WF, Brennan MC. Periconception warnings about prescribing opioids Am J Obstet Gynecol 2011;204(4)281-2 2p.

35. Yazdy MM, Mitchell AA, Tinker SC, Parker SE, Werler MM. Periconceptional use of opioids and the risk of neural tube defects. Obstet Gynecol 2013;122(4):83844.

36. Australian Bureau of Statistics. Australian Health Survey: Users' Guide, 2011-13 Survey Design and Operation. 2013 http://www.abs.gov.au/ausstats/abs@.nsf/ Latestproducts/D9707300945AE90FCA257B8D00229E78?opendocument. [Accessed 30 July 2015].

37. Australian Bureau of Statistics. Australian Health Survey: Users' Guide, 2011-13 Structure of the Australian Health Survey. 2013 http://www.abs.gov.au/ausstats/ abs@.nsf/Latestproducts/74D87E30B3539C53CA257BBB0014BB36?opendocument. [Accessed 10 October 2015].

38. Australian Bureau of Statistics. Australian Health Survey: Users' Guide, 2011-13 Female life stages. 2013 http://www.abs.gov.au/ausstats/abs@.nsf/Lookup/
0054B41EE12562AACA257B8D00229E95?opendocument. [Accessed 1 September 2016].

39. World Health Organisation. The Anatomical Therapeutic Chemical Classification System with Defined Daily Doses (ATC/DDD). 2003 http://www.who.int/ classifications/atcddd/en/. [Accessed 15 July 2016].

40. Bell P. Weighting and Standard Error Estimation for ABS Household Surveys. ABS Methodology Advisory Committee: Australian Bureau of Statistics; 2000.

41. Meyer M. The perils of opioid prescribing during pregnancy. Obstet Gynecol Clin North Am 2014;41(2):297-306.

42. Turk DC, Wilson HD, Cahana A. Treatment of chronic non-cancer pain. Lancet 2011;377(9784):2226-35.

43. Chou R, Fanciullo GJ, Fine PG, et al. Clinical guidelines for the use of chronic opioid therapy in chronic noncancer pain. J Pain 2009;10(2):113-30.

44. Johnson NS, Harwood EM, Nguyen RHN. You have to go through it and have your children: reproductive experiences among women with vulvodynia. BMC Pregnancy Childbirth 2015;15:114.

45. Meade T, Sharpe L, Hallab L, Aspanell D, Manolios N. Navigating motherhood choices in the context of rheumatoid arthritis: women's stories. Musculoskelet Care 2013;11(2):73-82.

46. Colvin L, Slack-Smith L, Stanley FJ, Bower C. Pharmacovigilance in pregnancy using population-based linked datasets. Pharmacoepidemiol Drug Saf 2009;18 (3):211-25.

47. Therapeutic Goods Administraion. Prescribing Medicines in Pregnancy Database. 2016 https://www.tga.gov.au/prescribing-medicines-pregnancy-database. [Accessed 20 May 2017].

48. Kennedy D. Analgesics and pain relief in pregnancy and breastfeeding. Aust Prescr 2011;34(1):8-10.

49. Henry A, Crowther C. Patterns of medication use during and prior to pregnancy: the MAP study. Aust N Z J Obstet Gynaecol 2000;40(2):165-72.

50. Therapeutic Goods Administration. Nonsteroidal Anti-Inflammatory Drugs (NSAIDs) and Spontaneous Abortion. Canberra: Australian Government Department of Health; 2016.

51. Shaheen SO, Newson RB, Smith GD, Henderson AJ. Prenatal paracetamol exposure and asthma: further evidence against confounding. Int J. Epidemiol 2010;39(3):790-4.

52. Stergiakouli E, Thapar A, Davey Smith G. Association of acetaminophen use during pregnancy with behavioral problems in childhood: evidence against confounding. JAMA Pediatr 2016;170(10):964-70. doi:http://dx.doi.org/ 10.1001/jamapediatrics.2016.1775.

53. Nahin RL. Estimates of pain prevalence and severity in adults: United States, 2012. J Pain 2015;16(8):769-80.

54. Australian Bureau of Statistics. Australian Health Survey: Users' Guide, 2011-13 Long Term Conditions: Other. 2013 http://www.abs.gov.au/ausstats/abs@.nsf/ Latestproducts/E961C216AABF42E0CA257B8E0016EA5F?opendocument. [Accessed 10 August 2016]. 